\title{
Frequency Survey of Bacterial Contamination of Mobile Cell Phones in General Population in Tehran, Iran
}

\author{
Esfandiar Matini ${ }^{1}$, Farzad Shayeghi ${ }^{1 凶}$, Javad Nematian ${ }^{1}$, Homeyra Shayeghi ${ }^{2}$, Vahideh lazemi ${ }^{3}$, Reihaneh Rezaeian \\ Ghahroud ${ }^{4}$, Fatemeh Shahbazi ${ }^{4}$, Seyed Amir Mahdi Madari Mohades ${ }^{5}$, Amin Zarghami ${ }^{6}$, Hossein Ghasemzadeh \\ Kolgar ${ }^{7}$, Helia Rahmani ${ }^{4}$, Hanieh Abasi Feshki ${ }^{8}$, Zahra Baghaee Barjin ${ }^{8}$
}

\author{
${ }^{1}$ Faculty of Medicine, Islamic Azad University, Tehran Medical Sciences Branch, Tehran, Iran \\ ${ }^{2}$ Islamic Republic of Iran Broadcasting (IRIB), Tehran, Iran \\ ${ }^{3}$ Faculty of Nursing, Islamic Azad University, Tehran Medical Sciences Branch, Tehran, Iran \\ ${ }^{4}$ Faculty of Biology, Department of Microbiology, Islamic Azad University, Tehran Medical Sciences Branch, Tehran, Iran \\ ${ }^{5}$ Faculty of Public Health, Islamic Azad University, Tehran Medical Sciences Branch, Tehran, Iran \\ ${ }^{6}$ Babol University of Medical Sciences, Babol, Iran \\ ${ }^{7}$ Student Research Committee, School of Public Health, Shahroud University of Medical Sciences, Sharoud, Iran \\ ${ }^{8}$ Islamic Azad University, Tehran Medical Sciences Branch, Tehran, Iran
}

\begin{abstract}
Background: Mobile smart phones have become increasingly integrated into the daily lives of individuals in society. Recent studies indicated the considerable role of these devices as reservoirs for various micro-organisms. The objective of this study was to assess the prevalence of microbiological contamination of mobile phones in general population.Materials and Methods: This cross-sectional study included a large sample of mobile phones of general population Tehran in 2015. Samples for culture were collected from mobile phones and transported for microbiological identification based on standard laboratory methods. Results: Bacteriological analysis revealed that in total of 5220 sample retrieved, 5180 (98.9\%) mobile phone devices were contaminated with bacteria. The most common microorganisms that were isolated include: Staphylococcus epidermidis (63.9), Escherichia coli (12.3\%) and Staphylococcus aureus (11.4\%). Conclusion: The prevalence of mobile phone contamination is high in general population in Tehran. Although most of the isolated organisms seemed to be non-pathogenic, their colonization may endanger certain populations particularly in health care settings.
\end{abstract}

[GMJ.2016;5(2):70-74]

Keywords: Mobile Phones; Hygiene; Contamination

\section{Introduction}

$\mathrm{T}_{\mathrm{b}}$ he global utilization of mobile phones has been accelerated in recent years. Nowadays, this technology has enormously affected different aspects of human life by its numerous applications and accessories [1,2]. Mobile

\section{GMJ}

2016 Galen Medical Journal

Fax: +98 7312227091

PO Box 7461686688

Email:info@gmj.ir phone due to its nature is easily accessible and constantly handled by owners in all places such as houses, hospitals, toilets, public stations, etc. Such environments have very high density of micro-organisms many of which are potentially pathogenic bacteria, and mobile phones could present as a major vehicle

\footnotetext{
Correspondence to:

Farzad Shayeghi, Faculty of Medicine, Islamic Azad University, Tehran Medical Sciences Branch, Tehran, Iran

Telephone Number: +9821-22006660

Email Address: farzadshayghi@gmail.com
} 
for transmission of these micro-organisms in the environment [3].

Previous studies have investigated the role of mobile phones in transmission of infection. But most of them were limited to health care settings $[4,5]$.

Microbiological studies revealed that bacterial growth on mobile phones of health care workers (HCWs) from hospitals was more than $15 \%$ which contained various types of bacterial and fungal contamination [6, 7]. Moreover, it has been demonstrated that HCWs' mobile phones provide a reservoir for many harmful pathogens which cause nosocomial infections [8]. Unfortunately, studies have indicated that most staff and patients do not regularly consider preventive measures and never clean their phones. This would increase the probability of cross-contamination of such bacteria on hands and mobile devices of HCWs to many different clinical settings and therefore it would increase the risk of nosocomial infection [9]. The risk of nosocomial infection depends on several factors: firstly, the ability of certain pathogens to remain viable on a surface; secondly, the rate at which contaminated surfaces are being touched, the context in which the patient is exposed, and the levels of contamination that cause the transmission. In this regard, the role of contaminated environmental surfaces in the transmission of healthcare-associated pathogens are critical [10].

According to the authors' knowledge, the number of studies considering the level of contamination among general population is scarce. Thus, the aim of the current study was to assess the frequency of microbiological contamination of mobile phones in general population.

\section{Materials and Methods}

\section{Study Design and Participants}

This cross-sectional study was conducted in Tehran, capital city of Iran 2015. The study population encompassed participants older than 15 years old from different occupational groups including HCWs, laborers, students, teachers, academic persons, marketers, employees, etc. through a non-randomized sampling method. The protocol of the study was approved by Islamic Azad University, Tehran Medical Sciences Branch review board. After explaining the objectives of the study to the participants, demographic information including age, gender, educational level and occupational status was retrieved by a researcher-made questionnaire.

\section{Sampling and Laboratory Methods}

Samples from mobile phones were collected while the researcher was filling the questionnaire, using sterile cotton swabs. Medical and laboratory students were trained by an expert microbiologist to perform sampling process in a standardized manner. Each swab was first moistened with distilled water and was rotated over the surface of both sides of the mobile phones together with the keypad or touchpad. If the participants carry more than one mobile phone, sampling was performed separately by extra swabs from each mobile phone. Between each sampling, disinfectant solution was used to disinfect the hands of the sample collectors to prevent cross contamination. Each sample was labelled with a unique identification code for further evaluation. The samples were kept in transport media and transported to the laboratory for culture within 24 hours of sampling. All swabs were immediately inoculated blood and plates together. Swabs were then sub-cultured on blood agar, Mc Conkey's (Sigma-Aldric, Germany), eosin methylene blue agar (Sigma-Aldric, Germany) and sabouraud dextrose agar plates, which then were incubated at $5-10 \% \mathrm{CO} 2$ at $35-37^{\circ}$ for $48 \mathrm{~h}$. Plates which showed no growth were reported as negative, while those showing any growth were reported as positive. Positive cultures were documented using a semi quantitative method whereby a single individual identified and counted dominant colonial types. Bacteria were identified according to standard protocol. Isolated organisms were processed according to colony morphology and gram stain, pigmentation, catalase, coagulase production and motility.

\section{Statistical Analysis}

Data were entered and analyzed using SPSS 18 statistical software. Chi-squared test was used through Fisher's exact test to investigate 
differences in categorical variables. $\mathrm{P}$ value less than 0.05 was considered significant.

\section{Results}

The average age of the participants screened was $23.6 \pm 6.6$ years; $2208(42.3 \%)$ were males and $3009(57.7 \%)$ were females. Demographic characteristics of the study population are described in Table-1.

In 5220 sample retrieved, bacteriological analysis revealed that samples from 5180 (98.9\%) mobile phone devices were contaminated with bacteria (2193 sample in male and 2967 sample in female, $\mathrm{P}=0.07$ ). There was no significant difference between Positive culture and demographic characteristics (Table-1). As indicated in Table-2, the most common isolated micro-organisms included: Staphylococcus epidermidis (63.9\%), Escherichia coli $(12.3 \%)$ and Staphylococcus aureus (11.4\%).

\section{Discussion}

According to our findings, $98.9 \%$ of mobile phone samples from all the study groups were found to be contaminated by bacterial agents. It has been documented that electronic devices such as personal digital tools had the potential for the transmission of nosocomial pathogens by isolating of bacterial agents [11].

Unfortunately, the number of studies conducted for microbiological evaluation of samples from mobile phones among general population is scarce. In a similar study in Nigeria, Akineymi and colleagues indicated that marketers and food vendors had the highest rate of bacterial contamination (37\%), followed by lecturers and students $(30.6 \%)$. This high prevalence was attributed to the poor hygienic and sanitary practices associated with low level of education among these individuals [12].

Table 1. Distribution of Demographic Variables Among Study Population

\begin{tabular}{lccc}
\hline \multirow{2}{*}{ Variables } & Frequency & \multicolumn{2}{c}{ Bacterial Culture Growth } \\
\cline { 3 - 4 } & N (\%) & Positive & Negative \\
\hline Sex & & & \\
Male & $2209(42.3 \%)$ & 2193 & 16 \\
Female & $3011(57.7 \%)$ & 2967 & 44 \\
\hline Age group & & & 1 \\
Below 20 & $312(6 \%)$ & 311 & 17 \\
$20-29$ & $1997(38.3 \%)$ & 1980 & 1 \\
$30-39$ & $1332(25.5 \%)$ & 1331 & 22 \\
$40-49$ & $872(16.7 \%)$ & 850 & 19 \\
Above 50 & $707(13.5 \%)$ & 688 & 11 \\
\hline Education Level & & & 13 \\
Lower diploma & $691(13.2 \%)$ & 680 & 21 \\
High School Diploma & $883(16.9 \%)$ & 880 & 16 \\
Academic undergraduate & $1650(31.6 \%)$ & 1635 & 9 \\
Academic graduate & $1996(38.3 \%)$ & 1994 & 8 \\
\hline Occupation Status & & & 8 \\
Laborer & $1076(20.6 \%)$ & 1060 & \\
Student, teacher or lecturer & $2044(39.2 \%)$ & 2035 & 644 \\
Health care worker & $663(12.7 \%)$ & 568 & 664 \\
Marketers & $576(11 \%)$ & & \\
Employee & $672(12.9 \%)$ & & \\
\hline
\end{tabular}


Table 2. Frequency of Micro-Organisms Species Identified from Mobile Phone Samples Among Study Population

\begin{tabular}{lc}
\hline \multicolumn{1}{c}{ Microbial species } & $\begin{array}{c}\text { Frequency } \\
\text { N (\%) }\end{array}$ \\
\hline Staphylococcus epidermidis & $3333(63.9 \%)$ \\
Escherichia coli & $642(12.3)$ \\
Staphylococcus aureus & $595(11.4 \%)$ \\
Bacillus subtilis & $138(2.6 \%)$ \\
Proteus vulgaris & $121(2.3 \%)$ \\
Actinomyces & $58(1.1 \%)$ \\
Klebsiella & $48(0.9 \%)$ \\
Streptococcus pyogenes & $47(0.9 \%)$ \\
Streptococcus pneumonia & $24(0.5 \%)$ \\
Pseudomonas & $15(0.3 \%)$ \\
Citrobacter & $15(0.3 \%)$ \\
Hemophilus influenza & $15(0.3 \%)$ \\
Acintobacter & $12(0.2 \%)$ \\
Mixed growth & $97(1.9 \%)$ \\
No growth & $60(1.1 \%)$ \\
\hline
\end{tabular}

There are various similar studies in hospital settings which investigated the microbial contamination of mobile phones. Selim and Abaza revealed that $100 \%$ of their tested mobile phones were contaminated with either single or mixed bacterial agents and the most prevalent bacterial contaminants were methicillin-resistant $S$. aureus and coagulase-negative staphylococci representing $53 \%$ and $50 \%$, respectively [13]. Their finding was consistent with previous studies by Utsun et al. and Ulger et al. who reported $100 \%$ and $94 \%$ levels of contamination $[6,14]$. Besides, there are other studies that reported lower rates of contamination [15-17]. In comparison with previous studies, our study population was the largest sample and this was the main strength of our study. Most of the above-mentioned studies were conducted among HCWs and the high rate of contamination seemed to be disappointing. One reason to explain such a high contamination rate among HCWs is believed to be the unconscious handling of mobile phones while providing health care services. Besides, there is a lack of awareness about nosocomial infections and the lack of awareness about the contamination of their devices by infectious microorganisms among this population [14]. Undoubtedly, microorganisms can be transferred from person to person or from objects to hands. However, currently, the direct association between mobile phone bacterial contamination and individual's status of infection is still unknown. Although, significant overlap between touch-pad smart phones and the skin microbiome of their owners has been identified in recent investigations. Therefore, fomites such as mobile phones can potentially introduce pathogens to areas such as neonatal units [18-20].

In order to reduce the risk of contamination, several pivotal actions including: staff education promotion, strict hand hygiene measures, guidelines on device cleaning and consideration of the restrictions regarding the use of mobile phone technology in certain high risk areas are recommended. Further investigations are required to primarily assess the knowledge, attitude and practice of general population regarding these issues and then evaluate the benefit of such intervention strategies on mobile phone contamination [2].

\section{Conclusion}

The frequency of mobile phone contamination is high in general population in Tehran. Although most of the isolated organisms seemed to be non-pathogenic, their colonization may endanger certain populations particularly in health care settings. Educating general population about infection control and underlining individuals' responsibility of infection control are recommended as an important aspect of controlling such infections.

\section{Conflict of Interest}

None declared. 


\section{References}

1. Blake H. Innovation in practice: Mobile phone technology in patient care. $\mathrm{Br} \mathrm{J}$ Community Nurs. 2008;13(4):162-5.

2. Brady RR, Verran J, Damani NN, Gibb AP. Review of mobile communication devices as potential reservoirs of nosocomial pathogens. J Hosp Infect. 2009;71(4):295-300.

3. Bhoonderowa A, Gookool S, Biranjia-Hurdoyal SD. The Importance of Mobile Phones in the Possible Transmission of Bacterial Infections in the Community. J Community Health. 2014;39(5):965-7.

4. Cavari Y, Kaplan O, Zander A, Hazan G, Shemer-Avni Y, Borer A. Healthcare workers mobile phone usage: A potential risk for viral contamination. Surveillance pilot study. Infect Dis (Lond). 2016;48(6):432-5.

5. Kilic IH, Ozaslan M, Karagoz ID, Zer Y, Davutoglu V. The microbial colonisation of mobile phone used by healthcare staffs. Pak J Biol Sci. 2009;12(11):882-4.

6. Ulger F, Dilek SEA, Yanik K, Gunaydin M, Leblebicioglu H. Are we aware how contaminated our mobile phones with nosocomial pathogens? Ann Clin Microbiol Antimicrob. 2009;8:7.

7. Jeske HC, Tiefenthaler $\mathrm{W}$, Hohlrieder $\mathrm{M}$, Hinterberger G, Benzer A. Bacterial contamination of anaesthetists' hands by personal mobile phone and fixed phone use in the operating theatre. Anaesthesia. 207;62:904-6.

8. Datta P, Rani H, Chander J, Gupta V. Bacterial contamination of mobile phones of health care workers. Indian J Med Microbiol. 2009;27(3):279-81.

9. Visvanathan A, Gibb AP, Brady RR. Increasing clinical presence of mobile communication technology: avoiding the pitfalls. Telemed J E Health. 2011;17(8):656-61.

10. Cataño JC, Echeverri LM, Szela C. Bacterial contamination of clothes and environmental items in a third-level hospital in Colombia. Interdiscip Perspect Infect Dis. 2012;2012:507640.

11. Bures S, Fishbain JT, Uyehara CF, Parker JM, Berg BW. Computer keyboards and faucet handles as reservoirs of nosocomial pathogens in the intensive care unit. Am J Infect Control. 2000;28(6):465-71.
12. Akinyemi KO, Atapu AD, Adetona OO, Coker AO. The potential role of mobile phones in the spread of bacterial infections. J Infect Dev Ctries 2009;3(8):628-32.

13. Selim HS, Abaza AF. Microbial contamination of mobile phones in a health care setting in Alexandria, Egypt. GMS Hyg Infect Control. 2015; 10:Doc03.

14. Ustun $\mathrm{C}$, Cihangiroglu M. Health care workers' mobile phones: a potential cause of microbial cross-contamination between hospitals and community. J Occup Environ Hyg. 2012;9(9):538-42.

15. Mark D, Leonard C, Breen H, Graydon R, O'Gorman C, Kirk S. Mobile phones in clinical practice: reducing the risk of bacterial contamination. Int J Clin Pract. 2014;68(9):10604.

16. Shakir IA, Patel NH, Chamberland RR, Kaar SG. Investigation of Cell Phones as a Potential Source of Bacterial Contamination in the Operating Room. J Bone Joint Surg Am. 2015;97:225-31.

17. Kumar BV, Hobani YH, Abdulhaq A, Jerah AA, Hakami OM, Eltigani M, et al. Prevalence of antibacterial resistant bacterial contaminants from mobile phones of hospital inpatients. Libyan J Med. 2014;9:25451

18. Meadow JF, Altrichter AE, Green JL. Mobile phones carry the personal microbiome of their owners. Peer J 2014;2:e447.

19. Goldblatt JG, Krief I, Klonsky T, Haller D, Milloul V, Sixsmith DM, et al. Use of cellular telephones and transmission of pathogens by medical staff in New York and Israel. Infect Control Hosp Epidemiol. 2007;28(14):500-3.

20. Orsi GB, Natale F, d'Ettorre G, Protano C, Vullo V, Curtis MD. Mobile phone microbial contamination among neonatal unit healthcare workers. Infect Control Hosp Epidemiol. 2015;36(4):487-9. 